Article

\title{
The Relationship between Soccer Club Coaches' Decision-Making Style, Basic Psychological Needs, and Intention to Continue to Exercise: Based on Amateur Male Soccer Club Members in Korea
}

\author{
YongKoo Noh ${ }^{1}$, Kyongmin Lee ${ }^{1, * \mathbb{C}}$ and Chul-Ho Bum ${ }^{2}$ \\ 1 Department of Policy Development, Korea Institute of Sport Science, Seoul 01794, Korea; ynoh@kspo.or.kr \\ 2 Graduate School of Physical Education, Kyung Hee University, Yongin-Si 17104, Korea; bch2180@khu.ac.kr \\ * Correspondence: dsukmlee@naver.com; Tel.: +82-10-3803-4857
}

Received: 19 August 2018; Accepted: 15 October 2018; Published: 18 October 2018

check for updates

\begin{abstract}
Numerous studies in sports science have investigated the relationships between coaching behavior, basic psychological needs, and intention to continue to exercise in sport participants in order to promote their continued exercise participation. However, little is known about the effect of the coach's decision-making style on sport participants' basic psychological needs and intention to continue to exercise. Thus, this study empirically investigated the relationship between these three variables. For this purpose, a survey was given to a convenience sample of 200 members of amateur male soccer clubs in Seoul and Gyeonggi, Korea. The results of multiple regression analysis showed that the type of coach that makes decisions based on a thorough analysis and reasonable evaluation of all possible solutions had a greater effect on the satisfaction of basic psychological needs and a greater effect on intention to continue to exercise in soccer club members than the types of coaches who use other styles of decision making in coaching. In addition, the intention to continue to exercise in soccer club members was higher when they voluntarily participated in soccer activities and when they made a strong emotional bond with the people they were exercising with. The findings of this study may provide the basic data on the coaches' decision-making style needed to improve sport participants' internal motivation and to stimulate their intention to continue to exercise.
\end{abstract}

Keywords: amateur soccer club; basic psychological needs; coach's decision-making style; intention to continue to exercise

\section{Introduction}

Sport participation helps people to maintain physical and mental health and lead happy lives. Continued sport participation is therefore highly important to maintain physical and mental health (Biddle and Mutrie 2007). One may become involved in sport activities, but encounter various reasons that make it extremely difficult to continue participating in a sport on a regular basis during the period of the activity. One study reported that approximately $50 \%$ of the people who initiated a sport activity quit the regime within six months (Marcus and Forsyth 2003). Some of the biggest reasons people quit their sport activity include the coach's coercive coaching style (Jung 2014), the risk of injury (Weiss and Petlichkoff 1989), the burden of exercise, and reduced motivation (Gould et al. 1985). If an individual drops out of a sport activity, it would cost him or her the physical, mental, and social benefits that the sport activity would have provided (Gould et al. 1985). For these reasons, major research topics in sports science include identifying the factors affecting exercise continuation in sport participants and finding efficient ways to improve the practice of continued exercise (Kohlstedt et al. 2013; McArthur et al. 2014; Somnil and Khaothin 2016). 
Motivation is possibly an important predictor of intention to continue to exercise, because it provides evidence as to whether an individual will not only choose and play a sport, but also continue the chosen activity (Sage 1977). Self-Determination Theory (SDT) is a useful theoretical tool for explaining why an individual regularly participates in, continues, and quits a sport (Hagger and Chatzisarantis 2007). SDT classifies motivation into internal motivation, external motivation, and amotivation according to the extent to which an individual chooses to play a sport themselves without the influence of external factors (Deci and Ryan 2008). Basic psychological needs theory, which is one of the subtheories of SDT, explains that internal motivation is expressed when the basic human psychological needs for autonomy, competence, and relatedness are satisfied, and external motivation is expressed when these desires are left unsatisfied (Martinez et al. 2013). In a sport situation, satisfaction with autonomy is achieved when one participates in a sport activity due to the individual's voluntary choice rather than external factors (Hollembeak and Amorose 2005), and satisfaction with competence is achieved when one feels an individual's athletic ability or skill is effectively exercised (Deci and Ryan 2008). Satisfaction with relatedness is achieved when an individual builds a strong emotional bond with the people he or she is exercising with (Hollembeak and Amorose 2005). Accordingly, individuals whose basic psychological needs have been satisfied demonstrate high levels of internal motivation. They get involved in playing sports not for external rewards, but for the pure pleasure that sports offer. Thus, they are more likely to continue participating in a sport activity than those whose basic psychological needs are not satisfied (Hagger and Chatzisarantis 2007).

Numerous existing studies have investigated the relationship between basic psychological needs and the intention to continue to exercise in sport participants. For example, Calvo et al. (2010) studied high school soccer players. They found that the intention to continue to exercise was high in subject athletes when their autonomy and relatedness were high, and that the intention to quit exercise was high when their autonomy and relatedness were low. Kim and Kim (2011) studied high school students on a humanities track and reported that the intention to continue to exercise in students became higher when their competence and relatedness were higher. Park and Kim (2011) studied a sample of undergraduate athletes and observed that autonomy had a negative effect and competence and relatedness a positive effect on the intention to continue to exercise in subjects. These results indicate that basic psychological needs in sport participants are important variables influencing their intention to continue to exercise.

Another variable that may influence the intention to continue to exercise is the coach's decision-making style. A coach as a decision maker is involved in a series of activities, ranging from simple duties to complex matters, such as choosing partners for practice, selecting strategies and tactics, and selecting athletes (Giske et al. 2013). Decision making refers to an individual's behavior in carefully reviewing various alternatives and opting for the optimal one to achieve organizational objectives efficiently (Dumler and Skinner 2007). All activities of an organization are executed based on decision making, and the decisions of the decision maker largely influence the direction of the organization and the behavior of organizational members (Sohail 2013). In the relationship between the coach and the athletes, decisions are made primarily by the coach. Because of this, a coach's decision-making style may influence the intention in sport participants to continue to exercise.

Many earlier studies examined the relationship between a coach's decision-making style and sport participants' intention to continue to exercise. Sunar et al. (2009) surveyed soccer players and coaches at a boys' high school. Soccer players showed lower levels of burnout with a democratic coach than with an authoritarian coach in terms of decision making. The study of Zordoshtian et al. (2012) of Iranian elite female volleyball players also reported that authoritarian coaches had a positive effect on the level of burnout among the volleyball players. On the other hand, the study of Jeon and Cho (2014) of high school athletes suggested that authoritarian coaches had a positive effect on the level of satisfaction in athletes. The results of these existing studies indicate that sport participants' intention to continue to exercise may vary depending on the coach's decision-making style. 
The decision-making style of a coach may be a determinant that either satisfies or undermines the basic psychological needs of sport participants. Coaching behaviors that support or control autonomy in coach-participant relationships are known to be a crucial variable influencing the psychological needs of sport participants (Bartholomew et al. 2011; Edmunds et al. 2008). Coaches who support autonomy respect the choices of sport participants and provide the relevant information required to achieve a given task. Coaches of this style encourage the participation of participants in the decision-making process and provide positive feedback. In this manner, they play the role of a helper, helping participants to take the lead in solving the problem at hand (Mageau and Vallerand 2003). Conversely, coaches who apply controlling coaching methods control the autonomy of sport participants using strategies such as pressure, surveillance, and external rewards. Coaches with this approach focus on making participants conform to their own ideas and instructions (Mageau and Vallerand 2003). In this context, coaches of the democratic decision-making style, who encourage sport participants to participate in decision making, will likely have a positive effect on sport participants' psychological satisfaction, compared to coaches of the authoritarian decision-making style, who make decisions themselves based on their own knowledge and experience as coaches. For example, the study of Hollembeak and Amorose (2005) of undergraduate athletes reported that democratic coaches had a positive effect on athletes' autonomy, whereas authoritarian ones had a negative effect on athletes' relatedness. As suggested by these examples, it is crucial to investigate which decision-making style has positive or negative effects on sport participants' basic psychological needs in sport situations in order to improve the latter's internal motivation.

As discussed, it is highly important to empirically investigate the relationships between the coach's decision-making style, participants' basic psychological needs, and their intention to continue to exercise in order to stimulate sport participants to continue participating in sports. Unfortunately, little research has been conducted on the relationships between these three variables. Although coaches' decision-making styles have been treated in several studies of the relationship between coaching behavior and athletes' motivation (Amorose and Horn 2000; Hollembeak and Amorose 2005) and there have been several studies on the relationship between coaching behavior and athletes' intention to continue to exercise (Cha et al. 2015; Jeon and Cho 2014; Kim and Jung 2016), decision-making styles were only categorized into two types, democratic and authoritarian. The decision-making style that an individual selects is determined by the situation in which the individual finds him- or herself when he or she makes a decision (Scott and Bruce 1995). It might be difficult to make a rational decision in an uncertain environment where it is difficult to judge rationally (Crié and Chebat 2013), while a situation that calls for quick judgment requires a fast decision. Accordingly, instead of dividing decision-making styles dichotomously into democratic and authoritarian, this study categorized the decision-making styles that the coach can use in a sport into rational, intuitive, dependent, avoidant, and spontaneous, as classified by Scott and Bruce (1995).

In this regard, the purpose of this study is to analyze the effect that a coach's decision-making style has on the basic psychological needs of those who are currently members of male soccer clubs, as well as on their intention to continue exercising. To this end, this study established the following research questions:

Research Question 1: What effect do the coach's rational, intuitive, dependent, avoidant, and spontaneous decision-making styles have on soccer club members' basic psychological needs of autonomy, competence, and relatedness?

Research Question 2: What effect do the coach's rational, intuitive, dependent, avoidant, and spontaneous decision-making styles have on soccer club members' intention to continue to exercise?

Research Question 3: What effect do soccer club members' basic psychological needs of autonomy, competence, and relatedness have on their intention to continue to exercise? 


\section{Methods}

\subsection{Sample}

The subjects of this study were male adults in amateur soccer clubs based in Seoul and the Gyeonggi Province, Korea. As of 2017, the number of male adults in amateur soccer clubs is estimated to be around 2300 across Korea, 116 in Seoul, and 518 in the Gyeonggi Province (Korea Football Association Home Page 2018). The questionnaire survey was performed by convenience sampling for about 60 days from April 2018. Researchers conducting the surveys were experienced and trained on how to perform the specific surveys. The researchers visited the clubs in person and collected data. Before the survey, the researchers fully explained the study to the subjects and obtained their consent for participation in the survey; they were asked to self-administer the questionnaire. In total, 220 questionnaire copies were distributed and a total of 200 copies were finally used for analysis, after excluding 20 with incomplete or missing answers. The general characteristics of the subjects are shown in Table 1 below.

Table 1. General Characteristics of Subjects $(n=200)$.

\begin{tabular}{cccc}
\hline & Category & Frequency & Percent \\
\hline \multirow{2}{*}{ Age } & $20 \mathrm{~s}$ & 33 & 16.5 \\
& $30 \mathrm{~s}$ & 57 & 28.5 \\
& $40 \mathrm{~s}$ & 65 & 32.5 \\
& 50 s or older & 45 & 22.5 \\
\hline \multirow{3}{*}{ Education } & High school diploma or lower & 21 & 10.5 \\
& Commity college student or graduate & 51 & 25.5 \\
& University student or graduate & 93 & 46.5 \\
& Master's degree or higher & 35 & 17.5 \\
\hline \multirow{2}{*}{ Occupation } & Student & 17 & 8.5 \\
& Professional & 29 & 14.5 \\
& Employee & 59 & 29.5 \\
& Public servant & 25 & 12.5 \\
\end{tabular}

\subsection{Measures}

A structured questionnaire was composed to identify factors influencing the intention to continue to exercise in male adult soccer club members. All question items were measured on a 5-point Likert scale, except for the general characteristics of subjects.

The General Decision Making Style (GDMS) was originally developed by Scott and Bruce (1995) to assess coaches' decision-making styles. The translated version by Kim et al. (2011) was used to meet the purpose of this study. The decision-making style was assessed with a total of 20 questions consisting of four questions on rational style; four on intuitive style; four on dependent style; four on avoidant style; and four on spontaneous style. As shown in Table 2, the five variables of decision-making style explained $70.957 \%$ of the total variance. The reliability coefficients of the five decision-making style subvariables ranged from 0.743 to 0.926 .

Table 2. Factor Analysis and Reliability Test of the General Decision Making Style (GDMS) Questionnaire.

\begin{tabular}{lcc}
\hline Item & Loadings & $\alpha$ \\
\hline Avoidant style & 0.926 \\
The coach delays making a decision whenever he can. & 0.920 \\
The coach often puts off making an important decision. & 0.893 \\
The coach postpones making a decision because he finds it uncomfortable to think & 0.861 \\
about decision-making. & 0.850 \\
The coach avoids making an important decision until he is under pressure. & \\
\hline
\end{tabular}


Table 2. Cont.

\begin{tabular}{ll}
\hline Item & Loadings \\
\hline Rational style & 0.872 \\
The coach considers a variety of options related to specified goals when making a & 0.849 \\
decision. & 0.842 \\
The coach mostly has rational evidence for making a decision. & 0.839 \\
The coach thinks carefully when making a decision. & 0.809 \\
The coach makes a decision logically and systematically. & 0.856 \\
\hline Dependent style & 0.825 \\
The coach makes a decision more easily when he gets support from other people. & 0.862 \\
The coach likes to have someone lead things in the right direction when making an & 0.800 \\
important decision. & 0.763 \\
The coach often needs help from other people when making an important decision. & \\
The coach uses other people's advice when making an important decision. & 0.852 \\
\hline Intuitive style & 0.836 \\
The coach tends to rely on his intuitions when making a decision. & 0.798 \\
The coach relies on his instincts when making a decision. & 0.790 \\
The coach trusts his internal feelings and reactions when making a decision. & 0.842 \\
The coach thinks it is more important to feel his decision is right than to have a & \\
rational reason when making a decision. & 0.798 \\
\hline Spontaneous style & 0.758 \\
\hline The coach generally makes a decision hastily. & 0.709 \\
The coach often makes impulsive decisions. & 0.667 \\
The coach makes a decision quickly. & 0.743 \\
\hline The coach often makes a decision unexpectedly without having a plan or preparation. & \\
\hline
\end{tabular}

An instrument used by Kim and Yang (2013) based on the questionnaires developed by Deci and Ryan (2001) and Vlachopoulos and Michailidou (2006) was used for the purpose of this study to assess basic psychological needs. The assessment tool consists of three subvariables with a total of 15 questions -5 questions each on autonomy, competence, and relatedness. The three subvariables of basic psychological needs explained $80.137 \%$ of the total variance. The reliability coefficients of the three subvariables of basic psychological needs ranged from 0.919 to 0.958 (see Table 3).

Table 3. Factor Analysis and Reliability Test of the Basic Psychological Needs Questionnaire.

\begin{tabular}{lc}
\hline Item & Loadings \\
\hline Relatedness & 0.958 \\
I have a good relationship with the people I am exercising with. & 0.925 \\
I really like the people I am exercising with. & 0.924 \\
The people I am exercising with treat me friendly. & 0.915 \\
I bond well with the people I am exercising with. & 0.856 \\
I get along with the people I am exercising with. & 0.821 \\
\hline Competence & 0.902 \\
I am confident I can do any skill, no matter how difficult it is. & 0.871 \\
I feel I am talented in a sport activity. & 0.865 \\
Other people tell me that I am good at sports. & 0.861 \\
A sport activity is one of the activities that I can do well. & 0.826 \\
I feel I have a sports skill when I am doing a sport activity. & \\
\hline Autonomy & 0.865 \\
I can freely decide what sport activity I want to do. & 0.861 \\
I have many opportunities to make a decision on my own when doing a sport activity. & 0.952 \\
I can freely express my thoughts and opinions about a sport activity. & 0.843 \\
I can freely do a sport activity without being bothered by others. & 0.749 \\
The sport activity I am doing now suits my interest and preferences. & \\
\hline
\end{tabular}


The tool used in the study of Cho and Kim (2008) based on the questionnaires developed by Couraeya and McAuley (1993) and Poff (2001) was used for the purpose of this study and was used to assess the intention to continue to exercise. This assessment tool consists of a single variable with four questions. These questions include, "I am confident that I can continue to exercise even if I am busy with my work," "I will continue to exercise even if I am tired," "I will continue to participate in a sports activity even if I do not have much time," and "I will continue to exercise even if the weather is not very good." The reliability coefficient was 0.884 .

\subsection{Data Analysis}

Data were processed using SPSS 23.0. The personal characteristics of the sample were analyzed through frequency analysis. The validity of the questionnaire was tested with exploratory factor analysis and its reliability using Cronbach's $\alpha$. Multiple regression analysis was conducted to test the relationships between decision-making style, basic psychological needs, and intention to continue to exercise. The tests of statistical significance levels in this study were all conducted with a significance level of $\alpha=0.05$.

\section{Results}

\subsection{Descriptive Statistics and Correlation Analysis}

As in Table 4, the factor levels of the coach's five decision-making styles were found higher in the order of rational $(M=3.91, S D=0.73)$, intuitive $(M=3.25, S D=0.70)$, dependent $(M=2.84, S D=0.85)$, spontaneous $(M=2.60, S D=0.93)$, and avoidant $(M=2.18, S D=0.00)$. The factor levels of soccer club members' three basic psychological needs were higher in the order of autonomy $(M=4.07, S D=0.80)$, relatedness $(M=4.39, S D=0.80)$, and competence $(M=4.10, S D=0.73)$. The mean of soccer club members' intention to continue to exercise was found at $3.57(S D=0.96)$.

Table 4. Correlations between Coach's Decision-Making Style, Basic Psychological Needs, and Intention to Continue to Exercise $(N=200)$.

\begin{tabular}{|c|c|c|c|c|c|c|c|c|c|c|c|}
\hline Variable & $M$ & $S D$ & 1 & 2 & 3 & 4 & 5 & 6 & 7 & 8 & 9 \\
\hline Rational & 3.91 & 0.73 & 1 & & & & & & & & \\
\hline Intuitive & 3.25 & 0.70 & $0.285^{* *}$ & 1 & & & & & & & \\
\hline Dependent & 2.84 & 0.85 & $-0.166^{*}$ & -0.015 & 1 & & & & & & \\
\hline Spontaneous & 2.60 & 0.93 & -0.084 & $0.275^{* *}$ & 0.033 & $0.407^{* *}$ & 1 & & & & \\
\hline Autonomy & 4.07 & 0.80 & $0.376^{* *}$ & $0.315^{* *}$ & -0.191 * & -0.104 & 0.070 & 1 & & & \\
\hline Competence & 4.10 & 0.73 & $0.258^{* *}$ & $0.256^{* *}$ & 0.077 & -0.041 & 0.030 & $0.294^{* *}$ & 1 & & \\
\hline $\begin{array}{l}\text { Intention to } \\
\text { continue to }\end{array}$ & 3.57 & 0.96 & $0.444 * *$ & $0.248^{* *}$ & $-0.189 * *$ & $-0.273 * *$ & 0.021 & $0.458^{* *}$ & $0.288^{* *}$ & $0.497^{* *}$ & 1 \\
\hline
\end{tabular}

exercise

${ }^{*} p<0.05,{ }^{* *} p<0.01$. Note. 1: Rational; 2. Intuitive; 3. Dependent; 4. Avoidant; 5. Spontaneous; 6. Autonomy; 7. Competence; 8. Relatedness; 9. Intention to Continue to Exercise.

A correlation analysis between decision-making style, basic psychological needs, and intention to continue to exercise found that the decision-making style subvariable of rational style was significantly positively correlated with all the subvariables of basic psychological needs $(r=0.376, p<0.01 ; r=0.258$, $p<0.01 ; r=0.323, p<0.01)$ and with intention to continue to exercise $(r=0.444, p<0.01)$. In addition, the decision-making style subvariable of intuitive style was significantly positively correlated with all the subvariables of basic psychological needs $(r=0.315, p<0.01 ; r=0.256, p<0.01 ; r=0.179$, $p<0.01)$ and with the intention to continue to exercise $(r=0.248, p<0.01)$. The decision-making style subvariable of the dependent style was negatively correlated with autonomy $(r=-0.191, p<0.01)$ and relatedness $(r=-0.140, p<0.01)$ subvariables of basic psychological desires, and the avoidant style was significantly negatively correlated with relatedness $(r=-0.199, p<0.01)$. These two styles were also significantly negatively correlated with the intention to continue to exercise $(r=-0.189$, 
$p<0.01 ; r=-0.273, p<0.01)$. On the other hand, all subvariables of basic psychological needs were significantly positively correlated with the intention to continue to exercise $(r=0.458, p<0.01 ; r=0.288$, $p<0.01 ; r=0.497, p<0.01$ ).

\subsection{Relationship between Coach's Decision-Making Style and Basic Psychological Desires}

The coach's decision-making style had a significant effect on the basic psychological needs of soccer club members. As shown in Table 5, the coach's decision-making style explained $21.7 \%$ of the variance in autonomy $\left(R^{2}=0.217, F=10.739, p<0.001\right)$; the rational $(\beta=0.282, p<0.001)$, intuitive $(\beta=0.223, p<0.01)$, and dependent styles $(\beta=-0.130, p<0.05)$ influenced autonomy, in that order. The coach's decision-making style explained $11.8 \%$ of the variance in competence $\left(R^{2}=0.118, F=5.183\right.$, $p<0.001)$, and the rational style $(\beta=0.214, p<0.01)$ made the strongest unique contribution to the prediction of competence. Finally, the coach's decision-making style explained $16 \%$ of the variance in relatedness $\left(R^{2}=0.160, F=7.385, p<0.001\right)$, and the rational style $(\beta=0.264, p<0.001)$ had the strongest unique contribution to explaining relatedness, followed by the avoidant style.

Table 5. Relationships between Coach's Decision-Making Style and Basic Psychological Needs $(N=200)$.

\begin{tabular}{|c|c|c|c|c|c|c|c|c|c|}
\hline \multirow{2}{*}{ Variable } & \multicolumn{3}{|c|}{ Autonomy } & \multicolumn{3}{|c|}{ Competence } & \multicolumn{3}{|c|}{ Relatedness } \\
\hline & $B$ & $S E B$ & $\beta$ & $B$ & $S E B$ & $\beta$ & $B$ & $S E B$ & $\beta$ \\
\hline Rational & 0.309 & 0.075 & $0.282 * * *$ & 0.212 & 0.073 & $0.214^{* *}$ & 0.289 & 0.078 & $0.264^{* * *}$ \\
\hline Intuitive & 0.253 & 0.079 & $0.223^{* *}$ & 0.206 & 0.076 & $0.200 * *$ & 0.101 & 0.082 & 0.089 \\
\hline Dependent & -0.122 & 0.061 & -0.130 * & 0.103 & 0.058 & 0.121 & -0.066 & 0.063 & -0.071 \\
\hline Avoidant & -0.079 & 0.057 & -0.098 & -0.036 & 0.055 & -0.050 & -0.173 & 0.059 & $-0.213^{* *}$ \\
\hline Spontaneous & 0.066 & 0.063 & 0.077 & 0.007 & 0.060 & 0.009 & 0.118 & 0.065 & 0.137 \\
\hline$R^{2}$ & \multicolumn{3}{|c|}{$0.217^{* * *}$} & \multicolumn{3}{|c|}{$0.118^{* * *}$} & \multicolumn{3}{|c|}{$0.160^{* * *}$} \\
\hline$F$ & \multicolumn{3}{|c|}{10.739} & \multicolumn{3}{|c|}{5.183} & \multicolumn{3}{|c|}{7.385} \\
\hline
\end{tabular}

\subsection{Relationship between Coach's Decision-Making Style and the Intention to Continue to Exercise}

As shown in Table 6, The coach's decision-making style had a significant effect on the intention to continue to exercise in soccer club members. This variable explained $28.7 \%$ of the variance in the intention to continue to exercise $\left(R^{2}=0.287, F=15.654, p<0.001\right)$. The rational $(\beta=0.356, p<0.001)$, avoidant $(\beta=-0.271, p<0.001)$, and intuitive styles $(\beta=0.141, p<0.05)$ most influenced the intention to continue to exercise, in that order. Among the coach's decision-making styles, however, the dependent $(\beta=-0.096, p=0.124)$ and spontaneous $(\beta=0.125, p=0.071)$ decision-making styles were found to have no statistically significant effect on soccer members' intention to continue to exercise.

Table 6. Relationships between Coach's Decision-Making Styles and the Intention to Continue to Exercise $(N=200)$.

\begin{tabular}{cccc}
\hline \multicolumn{4}{c}{ Intention to Continue to Exercise } \\
\hline Variable & $B$ & $S E B$ & $\beta$ \\
\hline Rational & 0.466 & 0.086 & $0.356^{* * *}$ \\
Intuitive & 0.191 & 0.090 & $0.141^{*}$ \\
Dependent & -0.107 & 0.069 & -0.096 \\
Avoidant & -0.262 & 0.065 & $-0.271^{* * *}$ \\
Spontaneous & 0.129 & 0.071 & 0.125 \\
$R^{2}$ & & $0.287^{* * *}$ & \\
$F$ & & 15.654 & \\
\hline \multicolumn{4}{c}{$p<0.05 .{ }^{* * *} p<0.001}$.
\end{tabular}




\subsection{Relationship between Basic Psychological Needs and Intention to Continue to Exercise}

As shown in Table 7, The basic psychological needs of soccer club members had a significant effect on the intention to continue to exercise. This variable explained $31.7 \%$ of the variance in the intention to continue to exercise $\left(R^{2}=0.317, F=30.353, p<0.001\right)$. Relatedness $(\beta=0.401, p<0.001)$ and autonomy $(\beta=0.267, p<0.001)$ had relatively strong effects on the intention to continue to exercise, in that order. Among soccer club members' basic psychological needs, however, competence $(\beta=0.098$, $p=0.125$ ) was found to have no statistically significant effect on their intention to continue to exercise.

Table 7. Relationships between Basic Psychological Needs and Intention to Continue to Exercise $(N=200)$.

\begin{tabular}{|c|c|c|c|}
\hline \multicolumn{4}{|c|}{ Intention to Continue to Exercise } \\
\hline Variable & $B$ & $S E B$ & $\beta$ \\
\hline Autonomy & 0.310 & 0.082 & $0.267^{* * *}$ \\
\hline Competence & 0.129 & 0.084 & 0.098 \\
\hline Relatedness & 0.401 & 0.083 & $0.336^{* * *}$ \\
\hline$R^{2}$ & & $0.317^{* * *}$ & \\
\hline$F$ & & 30.353 & \\
\hline
\end{tabular}

\section{Discussion}

The purpose of this study was to empirically investigate the relationship between coaches' decision-making styles, basic psychological needs, and intention to continue to exercise in male soccer club members. The following discussion is based on the results obtained.

First, the effect of coaches' decision-making style on the basic psychological needs in male soccer club members was assessed: Rational coaches had a positive effect on autonomy, competence, and relatedness, and intuitive coaches on autonomy and competence; conversely, dependent coaches had a negative effect on autonomy and avoidant coaches on relatedness. Rational coaches observed in this study had a greater effect on the satisfaction of basic psychological needs in soccer club members than coaches with other decision-making styles. Rational decision makers try to make decisions based on a thorough analysis and reasonable evaluation of all possible solutions (Scott and Bruce 1995). This result may show that soccer club members' satisfaction with basic psychological needs increases when the coach makes any important decisions based on various opinions from members during soccer activities and when the coach presents rational evidence as to why such decisions are important, instead of forcing members to blindly follow the decisions (Mageau and Vallerand 2003). Therefore, soccer club coaches should decide on achievable objectives suitable for the ability and capacity of club members based on information from members and other sources, as well as establish concrete training and game schedules to achieve the objectives one by one.

As noted earlier, the rational decision-making style can help to improve the basic psychological needs of soccer club members. However, it is not always possible for coaches to make rational decisions in all situations. Intuitive decision makers are characterized by using imagination, paying attention to current emotions, and using emotional awareness as the basis of decision making (Harren 1979). The intuitive decision-making style can be more effective in situations when it is difficult to determine the best course of action based on data and evidence and when one needs quick judgement (Giske et al. 2013). In particular, a study showed that the intuitive decision style of supervisor had a positive effect on employee empowerment (Gill et al. 2010). Therefore, coaches' use of rational or intuitive decision-making styles depending on the specific situation can contribute to improving autonomy and competence in soccer club members.

Dependent coaches allow the participation of others in the decision-making process and reflect their opinions during decision making (Scott and Bruce 1995). Therefore, it was expected that this style would have a positive effect on the basic psychological needs in soccer club members, as much as autonomy-supporting coaching behavior does. However, dependent coaches had a negative effect 
on members' autonomy, and they had no statistically significant effect on members' competence and relatedness. The study of Hollembeak and Amorose (2005) observed the conflicting result that democratic coaches had a positive effect on athletes' autonomy. This difference probably originates from the characteristics of the dependent decision-making style and the varying perspectives from which soccer club members interpret a coach's dependent decision-making style. Dependent coaches prefer depending on the help and advice of others when making an important decision (Scott and Bruce 1995). Another characteristic of this type of coach is that they depend on others' opinions and pass their responsibility on to them (Harren 1979). Members may consider a dependent decision-making style a democratic decision-making process, for example, by allowing the participation of members in the decision-making process and reflecting their opinions. In this case, the level of autonomy may increase when one feels that one's choice and decisions are respected (Hollembeak and Amorose 2005). Contrariwise, if the coach depends heavily on the decisions of club members, the latter may feel burdened by the responsibility of making their own decision. This sense of burden likely has a negative effect on club members' autonomy.

Second, the effect of a coach's decision-making style on the intention to continue to exercise in club members was assessed. Their intention to continue to exercise improved relatively more with a coach with a rational decision-making style than one with an intuitive style, and the intention decreased when the coach's decision-making style was avoidant. These results likely stem from the different processes through which rational and avoidant decision makers reached a decision and the ways they took responsibility. A rational decision maker seeks to find a reasonable solution by comparing various alternatives rather than avoiding making a decision. This type of decision maker takes responsibility for their own decision (Harren 1979). An avoidant decision maker feels insecure when making a decision, as they lack confidence and believe that they are unable to make the right decision. This type of decision maker tends to postpone decision making until the last possible moment (Scott and Bruce 1995). Taking this into account, soccer club members felt more satisfied when practicing with a rational coach than with an avoidant one, and this is highly likely to serve as a positive factor in stimulating them to continue participating in exercise.

Third, the subvariables of basic psychological needs in soccer club members of autonomy and relatedness had a statistically significant positive effect on the intention to continue to exercise, whereas competence did not have any significant effect. It was observed that their intention to continue participating in the soccer activity increased more as their relatedness and autonomy were more satisfied. The study of Calvo et al. (2010) surveyed adolescent soccer players and reported that the basic psychological desires of autonomy and relatedness were important precedents of the intention to continue to exercise. This finding supports the results of this study.

Autonomy is a major determinant of internal motivation among the different kinds of basic psychological needs (Ryan and Deci 2000). People have a strong tendency to continue to exercise when they have a high level of internal motivation. This is because those with a high level of internal motivation voluntarily participate in exercise not because of external factors, but for the joy that exercise itself provides (Ryan and Deci 2000). In light of this, the result that the satisfaction of the desire for autonomy leads to continued participation in exercise in soccer club members seems quite valid. Because individuals with high autonomy participate in exercise based on their own decision rather than the influence of external factors, they tend to be motivated less by external reasons than those with low autonomy. This can produce positive results with respect to continued practice of sports.

In this study, the desire for relatedness had a greater impact on members' intention to continue to exercise than the desire for autonomy. It is understood that this result likely stems from the strong collectivism prevalent in Korean society. Under the influence of this collective culture, Korean society emphasizes collective bonds and values interpersonal relationships more than individuals. It is also characterized by its strong tendency to respect the hierarchy between junior and senior members. In this environment, maintaining positive interpersonal relationships between coaches, colleagues, and senior and junior members may have a positive effect on the intention to continue to exercise in 
soccer club members. This is to say, contrariwise, conflicts between them can have a negative effect on their intention to continue to exercise (Kwon et al. 2015). Based on this discussion, it is recommended that coaches create a club culture that respects each member so as to increase members' intention to continue to exercise. Coaches must also detect arguments or conflicts between members through continued conversation.

\section{Conclusions}

Existing studies on the relationship between coaching behavior, basic psychological needs, and intention to continue divided coach's decision-making styles simply into authoritarian and democratic styles. However, this study attempted to take a different approach. It categorized coaches' decision-making styles into rational, intuitive, dependent, avoidant, and spontaneous, and examined what effect each of the decision-making styles had on sport participants' basic psychological needs and intention to continue to exercise. This study's results showed that coaches' rational and intuitive decision-making styles have a positive effect on the participants' basic psychological needs, while coaches' dependent and avoidant styles have a negative effect on their basic psychological needs. Furthermore, this study also revealed that coaches' rational and intuitive decision-making styles have a positive effect on sport participants' intention to continue to exercise, while coaches' avoidant style has a negative effect on their intention to continue to exercise. The findings of this study may serve as basic data for determining an efficient decision-making style for coaches that will satisfy the basic psychological needs of sport participants and promote their continued participation in exercise.

Despite these valuable findings, this study has shown several limitations throughout the course of investigation. The following is proposed accordingly. First, it is hard to generalize the results of this study because the subjects were members of soccer clubs based in specific regions. Future studies should investigate whether the similar significant relationships between the variables studied in this work also appear in other regions and sports. Second, the coaches' decision-making style investigated here was limited to male coaches' decision making. The preferred style of decision making can vary depending on gender (Loo 2000; Park 1996). It is recommended that multiple-group structural equation modeling be applied to investigate the moderating effect of gender on the relationship between coaches' decision-making style, basic psychological needs, and intention to continue to exercise. Furthermore, there are many more variables than gender that moderate and mediate the relationships between these three variables. Future studies should take such variables into account in their investigation. Lastly, coaches' decision-making styles could be affected by situational factors inside or outside the organization, such as a sports organization's atmosphere (Amorose and Horn 2000) and organizational structure (Miller 1987). A coach's personality characteristics could have an effect on their decision-making style. Accordingly, a follow-up study would need to identify important antecedents for coaches' decision-making styles to find an effective decision-making style that could have a positive effect on the basic psychological needs and intention to continue to exercise of participants in other sports.

Author Contributions: Y.N. made substantial contributions to drafting of manuscript and study conception and design. K.L. performed analysis on all samples, interpreted data and acted as corresponding author. K.L. and C.-H.B. collected data and helped to interpret data and evaluate and edit the manuscript. All authors have read and approved the final version submitted for publication, and agree to the order in which the authors are listed.

Funding: This research received no external funding.

Conflicts of Interest: The authors declare no conflict of interest.

\section{References}

Amorose, Anthony J., and Thelma S. Horn. 2000. Intrinsic Motivation: Relationships with Collegiate Athletes' Gender, Scholarship Status, and Perceptions of Their Coaches' Behavior. Journal of Sport E Exercise Psychology 22: 63-84. [CrossRef] 
Bartholomew, Kimberley J., Nikos Ntoumanis, Richard M. Ryan, Jos A. Bosch, and Cecilie Thøgersen-Ntoumani. 2011. Self-Determination Theory and Diminished Functioning: The Role of Interpersonal Control and Psychological Need Thwarting. Personality and Social Psychology Bulletin 37: 1459-73. [CrossRef] [PubMed]

Biddle, Stuart J. H., and Nanette Mutrie. 2007. Psychology of Physical Activity: Determinants, Well-Being and Interventions. New York: Taylor \& Francis.

Calvo, García T., Eduardo Cervelló, Ruth Jiménez, Damián Iglesias, and Antonio M. Murcia. 2010. Using Self-Determination Theory to Explain Sport Persistence and Dropout in Adolescent Athletes. The Spanish Journal of Psychology 13: 677-84. [CrossRef]

Cha, Hyun-Jung, Tea-Hong Kim, and Sun-Ho Mun. 2015. The Influence of Types of Dance Sports Instructors on Exercise Commitment, Exercise Satisfaction and Exercise Adherence. Journal of Sport and Leisure Studies 62: 497-507.

Cho, Eun Young, and Soo Hyun Kim. 2008. The Relationships among the Degree of Participation Motivation, Constant Intention of Participation and the Interpersonal Relations Disposition of the General Physical Education Program in University Students. Journal of Korean Association of Physical Education and Sport for Girls and Women 22: 213-25.

Couraeya, Kerry S., and Edward McAuley. 1993. Predicting Physical Activity from Intention: Conceptual and Methodological Issues. Journal of Sport E Exercise Psychology 15: 50-62.

Crié, Dominique, and Jean-Charles Chebat. 2013. Health Marketing: Toward an Integrative Perspective. Journal of Business Research 66: 123-26. [CrossRef]

Deci, Edward L., and Richard M. Ryan. 2008. Self-Determination Theory: A Macro theory of Human Motivation, Development, and Health. Canadian Psychology 49: 182-85. [CrossRef]

Deci, Edward L., and Richard M. Ryan. 2001. Questionnaires: Basic Psychological Needs Scales. Available online: http:/ / www.psych.rochester.edu/SDT/measures/needs.html (accessed on 11 September 2001).

Dumler, Michael P., and Steven J. Skinner. 2007. Primer for Management, 2nd ed. Boston: South-Western College Pub.

Edmunds, Jemma, Nikos Ntoumanis, and Joan L. Duda. 2008. Testing a Self-Determination Theory-Based Teaching Style Intervention in the Exercise Domain. European Journal of Social Psychology 38: 375-88. [CrossRef]

Gill, Amarjit, Alan Flaschner, Charul Shah, and Ishann Bhutani. 2010. The Relations of Transformational Leadership and Empowerment with Employee Job Satisfaction: A Study among Indian Restaurant Employees. Business and Economics Journal BEJ-18: 1-10.

Giske, Rune, Beate Benestad, Kristin Haraldstad, and Rune Høigaard. 2013. Decision-Making Styles among Norwegian Soccer Coaches: An Analysis of Decision-Making Style in Relation to Elite and Non-Elite Coaching and Level of Playing History. International Journal of Sports Science E Coaching 8: 689-701.

Gould, Daniel, Deborah Feltz, and Maureen Weiss. 1985. Motives for Participating in Competitive Youth Swimming. International Journal of Sport Psychology 16: 126-40.

Hagger, Martin, and Nikos Chatzisarantis. 2007. Intrinsic Motivation and Self-Determination in Exercise and Sport. Champaign: Human Kinetics.

Harren, Vincent A. 1979. A Model of Career Decision Making for College Students. Journal of Vocational Behavior 14: 119-33. [CrossRef]

Hollembeak, Jill, and Anthony Amorose. 2005. Perceived Coaching Behaviors and College Athletes' Intrinsic Motivation: A Test of Self-Determination Theory. Journal of Applied Sport Psychology 17: 20-36. [CrossRef]

Jeon, Young-Chun, and Hyun-Choul Cho. 2014. The Effect on Exercise Duration by Player Satisfaction according to Leadership Style of the Leader. Journal of the Korea Entertainment Industry Association 8: 493-501. [CrossRef]

Jung, Sung-Woo. 2014. Conceptual Structure of Dropout for Gymnastics and Development of Dropout Scale. Korean Journal of Sport Psychology 25: 119-36. [CrossRef]

Kim, Yuna, and Eun Hwa Jung. 2016. Effect of Types of Badminton Coaches on Players' Life Satisfaction, and Commitment Sustained Exercise. The Korean Journal of Sport 14: 637-46.

Kim, Kae Ju, and Deok Jin Kim. 2011. Structural Relationships among Student's Perceived Teaching Behavior, Basic Psychological Needs Satisfaction and Exercise Adherence Intention in High School Physical Education Class. Korean Society for the Study of Physical Education 16: 77-92.

Kim, Deok-Jin, and Myung-Hwan Yang. 2013. Development of Basic Psychological Need Satisfaction Scale in Sport and Model Verification within Self-Determination Theory. Korean Journal of Sport and Exercise Psychology 24: 29-58. 
Kim, Eun Joo, Jeong Il Kim, Seung Kyu Nam, and Gil Kwang Roh. 2011. Validation of General Decision Making Styles Scale. The Korean Journal of Consumer and Advertising Psychology 12: 751-70.

Kohlstedt, Sarah S., Carol S. Weissbrod, Anna M. Colangelo, and Michele M. Carter. 2013. Psychological Factors Influencing Exercise Adherence among Females. Psychology 4: 917-23. [CrossRef]

Korea Football Association Home Page. 2018. Available online: http:/ /www.kfa.or.kr/kfa/data_room.php?act= registration (accessed on 24 September 2018).

Kwon, Hyun-Jin, Dong-Ho Lee, and Ho-Sang Yoo. 2015. Relationship among Stress, Intrinsic Motive, and Continuous Participation in College Athletes. Journal of Coaching Development 17: 109-16.

Loo, Robert. 2000. A Psychometric Evaluation of the General Decision-Making Style Inventory. Personality and Individual Differences 29: 895-905. [CrossRef]

Mageau, Genevieve A., and Robert J. Vallerand. 2003. The Coach-Athlete Relationship: A Motivational Model. Journal of Sports Science 21: 883-904. [CrossRef] [PubMed]

Marcus, Bess. H., and Leigh Ann H. Forsyth. 2003. Motivating People to Be Physically Active. Champaign: Human Kinetics.

Martinez, Jennifer V., Crystal D. Oberle, and Alexander J. Nagurney. 2013. Basic Psychology Needs in Predicting Exercise Participation. Advances in Physical Education 3: 20-27. [CrossRef]

McArthur, Deanne, Alex Dumas, Kirsten Woodend, Sarah Beach, and Stacey Dawn. 2014. Factors Influencing Adherence to Regular Exercise in Middle-Aged Women: A Qualitative Study to Inform Clinical Practice. BMC Womens Health 14: 49. [CrossRef] [PubMed]

Miller, Danny. 1987. Strategy Making and Structure: Analysis and Implications for Performance. Academy of Management Journal 30: 7-32. [CrossRef]

Park, Daewoo. 1996. Gender Role, Decision Style and Leadership Style. Women in Management Review 11: 13-17. [CrossRef]

Park, Dong Soo, and Sung Mun Kim. 2011. The Relationship among Basic Psychological Need, Emotional, and Intention of Exercise Adherence of College Student Athletes. Korean Society for the Study of Physical Education 16: 197-209.

Poff, Raymond. 2001. Understanding the Relationships between Involvement, Commitment and Future Behavior Intentions of Kayakers and Canoeists Using Structural Equation Modeling. Doctoral dissertation, Indiana University, Bloomington, IN, USA.

Ryan, Richard M., and Edward L. Deci. 2000. Intrinsic and Extrinsic Motivations: Classic Definitions and New Directions. Contemporary Educational Psychology 25: 54-67. [CrossRef] [PubMed]

Sage, George H. 1977. Introduction to Motor Behavior: A Neuropsychological Approach, 2nd ed. Reading: Addison-Wesley.

Scott, Susanne G., and Reginald A. Bruce. 1995. Decision-Making Style: The Development and Assessment of a New Measure. Educational and Psychological Measurement 55: 818-31. [CrossRef]

Sohail, Talat. 2013. Decision Making Style of Women University Teachers. Journal of the Research Society of Pakistan 50: 190-206.

Somnil, Poosanapas, and Thawichai Khaothin. 2016. Factors Affecting Exercise Adherence Behavior of University Students in Upper Northeastern, Thailand. Canadian Center of Science and Education 12: 205-12. [CrossRef]

Sunar, Inderjit Goman Sing, Mohd. Sofian Omar-Fauzee, and Aminuddin Yusof. 2009. The Effect of School Coaches Decision-Making Style and Burnout on School Male Soccer Players. European Journal of Social Sciences 8: 672-82.

Vlachopoulos, Symeon P., and Sotiria Michailidou. 2006. Development and Initial Validation of a Measure of Autonomy, Competence, and Relatedness in Exercise: The Basic Psychological Needs in Exercise Scale. Measurement in Physical Education and Exercise Science 10: 179-201. [CrossRef] 
Weiss, Maureen R., and Linda M. Petlichkoff. 1989. Children's Motivation for Participation in and Withdrawal from Sport: Identifying the Missing Links. Pediatric Exercise Science 1: 195-211. [CrossRef]

Zordoshtian, Shirin, Rasool Norouzi Seyed Hossini, and Younis Mohammadzade. 2012. The Relationship between Leadership Styles of Coaches with Self-Determination and Burn-Out out of the Iranian Elite Female Volleyball Players. International Journal of Academic Research in Business and Social Science 2: 30-37. 